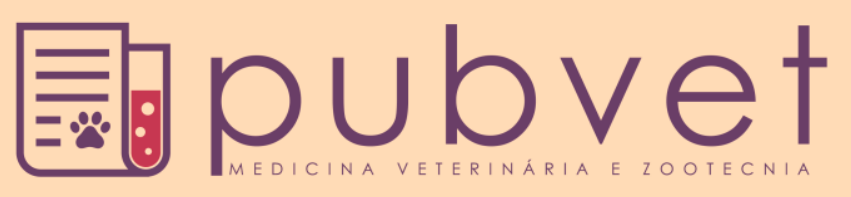

https://doi.org/10.22256/pubvet.v12n6a120.1-13

\title{
Prejuízos econômicos por condenação de vísceras vermelhas de suínos abatidos em Santa Catarina
}

\author{
Anilce de Araújo Bretas ${ }^{1 * \odot}$, Gustavo Perdoncini2 ${ }^{\bullet}$, Micheli Willemann² \\ ${ }^{I}$ Professor do Centro Universitário Barriga Verde, Departamento de Medicina Veterinária, Orleans, SC, Brasil. *Autor para correspondência. \\ E-mail: aabrettas@hotmail.com, micheliwillemann@hotmail.com \\ ${ }^{2}$ Discente do Centro Universitário Barriga Verde, Departamento de Medicina Veterinária, Orleans, SC, Brasil. E-mal: \\ gustavo.perdoncini@yahoo.com
}

RESUMO. O presente trabalho tem por objetivo apresentar dados coletados em 11 propriedades que abastecem um frigorífico de Santa Catarina. Foram analisados 2.691 suínos abatidos no ano de 2016 sobre as principais causas de condenações de vísceras vermelhas ou comestíveis em abates. Foram identificadas as seguintes causas por condenações de carcaças: pneumonia enzoótica 52,08\%, aspiração por sangue 20,28\%, aspiração por líquido $17,01 \%$, aderência de pleura $3,04 \%$, atelectasia pulmonar $0,89 \%$, enfisema pulmonar $0,18 \%$, abscesso pulmonar $0,26 \%$, pleuropneumonia $2,52 \%$, lesão por Ascaris suum $16,05 \%$, perihepatite $1,89 \%$, cirrose hepática 3,04\% e pericardite $6,91 \%$. As principais condenações foram por pneumonia enzoótica, aspiração por sangue, lesão por Ascaris suum e pericardite. Durante a inspeção as lesões podem ser provenientes de diferentes fatores, entre eles, falhas no processo tecnológico de abate, ausência de um programa de vacinação e erros de biossegurança nas propriedades, associado com o manejo precário. Diante disso, a redução da prevalência das lesões que culminam em condenação das carcaças pode ser minimizada com o treinamento de funcionários para minimizar as perdas econômicas na indústria e para os produtores de suínos juntamente com um rigoroso controle sanitário nas granjas.

Palavras-chave: carcaças, inspeção sanitária, lesões post mortem, suínos terminados

\section{Economic damages by condemnation of viscera in red of pigs slaughtered Santa Catarina}

ABSTRACT. The present work has as objective, with data collected in 11 properties that provide a refrigerator of Santa Catarina. A total of 2.691 pigs slaughtered in 2016 were analyzed as the main causes of condemnation of red or edible viscera in slaughter. Encephalic pneumonia $52.08 \%$, blood aspiration $20.28 \%$, fluid aspiration $17.01 \%$, pleural adhesion $3.04 \%$, pulmonary atelectasis $0.89 \%$, pulmonary emphysema $0.18 \%$, pulmonary abscess $0.26 \%$, pleuropneumonia $2.52 \%$, Ascaris suum lesion $16.05 \%$, perihepatitis $1.89 \%$, cirrhosis $3.04 \%$ and pericarditis $6.91 \%$. As main condemnations for enzootic pneumonia, blood aspiration, Ascaris suum injury and pericarditis. During the inspection as lesions can be disclosed of different factors, associated with precarious management, absent from a vaccination program and biosafety errors in properties, associated with poor management. In view of this, a reduction in the prevalence of injuries that culminate in condemnation of carcasses can be minimized by training employees to minimize economic losses in industry and to pig producers with strict sanitary control on farms.

Keywords: carcasses, sanitary inspection, finished swine, post mortem lesions 


\title{
Pérdidas económicas por condena de vísceras en rojo de cerdos sacrificados Santa Catarina
}

\begin{abstract}
RESUMEN. El presente trabajo tiene por objetivo presentar datos recogidos en 11 propiedades que abastecen un frigorífico de Santa Catarina. Se analizaron 2,691 cerdos sacrificados en el año 2016 sobre las principales causas de condenas de vísceras rojas o comestibles en sacrificios. Se identificaron las siguientes causas por condenas de canales: neumonía enzoótica 52,08\%, aspiración por sangre 20,28\%, aspiración por líquido 17,01\%, adherencia de pleura $3,04 \%$, atelectasia pulmonar $0,89 \%$, enfisema pulmonar El 0,18\%, absceso pulmonar $0,26 \%$, pleuropneumonía 2,52\%, lesión por Ascaris suum 16,05\%, perihepatitis $1,89 \%$, cirrosis hepática $3,04 \%$ y pericarditis $6,91 \%$. Las principales condenas fueron por neumonía enzoótica, aspiración por sangre, lesión por Ascaris suum y pericarditis. Durante la inspección las lesiones pueden provenir de diferentes factores, entre ellos, fallas en el proceso tecnológico de sacrificio, ausencia de un programa de vacunación y errores de bioseguridad en las propiedades, asociado con el manejo precario. Por lo tanto, la reducción de la prevalencia de las lesiones que culminan en la condena de las canales puede ser minimizada con el entrenamiento de funcionarios para minimizar las pérdidas económicas en la industria y para los productores de cerdos junto con un riguroso control sanitario en las granjas.
\end{abstract}

Palabras clave: carcasas, inspección sanitaria, lesiones post mortem, cerdos terminados

\section{Introdução}

A suinocultura atualmente é representada no mercado internacional pelos seguintes países EUA, União Europeia, Canadá, e Brasil. O consumidor brasileiro está cada vez mais exigente a respeito da qualidade higiênico-sanitária do seu produto, já que se o mesmo estiver fora dos padrões estabelecidos pela legislação vigente ocasionará sérios danos à saúde pública (ABIPECS, 2011).

No Brasil, em média são abatidas 34,9 milhões de cabeças por ano, sendo que na região do Sul está concentrado 66\% dos abates de suínos, Minas Gerais $11,8 \%$ e o restante $22,2 \%$ nos demais estados nacionais (SEAB, 2013). A produção de carne suína nacional obteve um crescimento médio anual de $8 \%$, com justificativa na melhoria dos sistemas produtivos e da tecnologia na produção ( $\underline{\text { SEAB, 2013) }}$.

O Serviço de Inspeção Estadual (SIE) desempenha as atividades de controle e fiscalização de matadouros, indústrias de produtos de origem animal propiciando a oferta de produtos seguros para o consumo da população.

O estado de Santa Catarina é o maior exportador de carne suína com $35,8 \%$, em seguida o Rio Grande do Sul com $29,6 \%$ e em terceiro Goiás com $12,4 \%$, onde é considerado o que mais evoluiu nas exportações de carne suína ( $\underline{\mathrm{SEAB}}$, 2013).
A Região Sul do Brasil respondeu por $66,9 \%$ do abate nacional de suínos, considerando o $1^{\circ}$ trimestre de 2017, sendo seguida pelas Regiões Sudeste (17,6\%), Centro-Oeste (14,5\%), Nordeste $(0,9 \%)$ e Norte $(0,1 \%)$. Entre os Estados ocorreram aumentos em termos de produção: Santa Catarina, Mato Grosso, Paraná, Minas Gerais, Mato Grosso do Sul, Goiás de acordo com o IBGE (2017).

O trabalho objetivou divulgar as pesquisas mais recentes sobre as condenações de vísceras comestíveis de suínos abatidos e as condenações de vísceras de suínos da região de Santa Catarina, em matadouro frigorífico sob Sistema de Inspeção Estadual (SIE) no ano de 2016.

\section{Procedimentos Metodológicos}

O presente artigo buscou abordar a importância que tem um levantamento bibliográfico atualizado, usando conceitos técnicos de práticas realizadas no campo pelos suinocultores, especificamente sobre as condenações de carcaças de suínos.

As referências documentadas foram selecionadas através de uma revisão sistemática de documentos escritos em artigos científicos nacionais e internacionais, e empresas brasileiras voltadas à pesquisa, seguindo um ordenamento de procedimentos teóricos sobre cada assunto técnico. 
Para a análise dos materiais citados ocorreram leituras seletivas que pudessem determinar os assuntos que de fato seriam interessantes e ao mesmo tempo relevantes ao objetivo do trabalho. Posteriormente, os itens foram selecionados e consequentemente relacionados através de dados pertinentes ou informações que agregariam a proposta de buscar informações sobre as condenações das vísceras de suínos na região.

Foram estudados 2.691 animais da espécie suína oriundos, de 11 propriedades, localizadas nos municípios de Rio Fortuna, Braço do Norte, Orleans, Grão Pará e Armazém e no frigorífico do município de Braço do Norte sob fiscalização do Serviço de Inspeção Estadual (SIE) foram analisados os relatórios mensais no ano de 2016 das estatísticas de abate de suínos e posteriormente compilados os números e as causas de condenações. Os dados foram organizados sobre as principais patologias que levaram ao descarte de vísceras e a avaliação das vísceras comestíveis incluindo coração, pulmão e fígado foi de acordo com o manual de Regulamento de Inspeção Industrial e Sanitária de Produtos de Origem Animal (RIISPOA). Todas as vísceras passaram por inspeções, seguindo a linha de abate que foi realizada de acordo com o manual de Regulamento de Inspeção Industrial e Sanitária de Produtos de Origem Animal (Brasil, 2001).

\section{Mercado consumidor de carne suína}

O Brasil é o quarto no ranking de produção de suínos, de acordo com o Ministério da Agricultura Pecuária e Abastecimento (MAPA) e Associação Brasileira de Proteína Animal (ABPA) no conceito de produção e exportação mundial de carne, produzindo 3,3 milhões de toneladas anualmente, sendo deste total 600 mil toneladas exportadas para 70 países (ABIPECS, 2011).

Toda a produção de carne deve ter alta tecnologia e com total controle de processos para a produção de carne com elevados padrões de qualidade. Assim, o reconhecimento da carne suína internacionalmente dentre outras características foi através do sabor e textura única, além de reduzidos níveis de gordura e por ser extremamente saudável em virtude do seu modelo de criação (ABPA, 2014). De acordo com Castro et al. (2014), a indústria suinícola vem crescendo e garantindo espaço no mercado alimentício, principalmente pela preferência por esta carne e seus processados por parte do mercado consumidor.
A suinocultura tem alta capacidade de reprodução como produtora de proteína animal de qualidade que atende a crescente demanda da população mundial. Alguns fatores podem ser responsáveis por afetarem as carcaças, como a genética, manejo, estado sanitário, nutrição e transporte dos animais (Giovanni et al., 2014).

O sistema de criação intensivo de suínos assegura importantes aspecto referentes ao controle de manejo, uniformidade dos lotes e boa relação custo e benefício. Contudo, o confinamento intensivo ocasionou um aumento de doenças na produção devido ao número expressivo de animais por área, assim como preocupações com o bem-estar (Sobestiansky et al., 1991).

\section{Inspeção sanitária: aspecto geral}

Durante o abate de suínos a inspeção é amplamente utilizada para avaliar a saúde dos rebanhos, assim como a prevalência de lesões dos animais destinados ao abate. Logo após a inspeção das cabeças, as vísceras são retiradas e os órgãos colocados em bandejas presas a uma esteira, que deverá manter a correlação da víscera com a carcaça na nórea (Bueno, 2012).

As vísceras brancas, que correspondem aos intestinos, estômago, bexiga e baço são colocadas em bandeja grande. Já as vísceras vermelhas, como pulmão, fígado, rins, coração e língua são colocadas em bandejas pequenas. Quando a víscera vermelha for descartada pela Inspeção Federal será colocada em bandejas grandes, o que indica que não poderá ser usada para comercialização. Ao fim da esteira os órgãos descartados caem para o processamento de subprodutos (Brasil, 2001).

A inspeção sanitária das carnes é importante para garantir a qualidade e reduzir o risco de transmissão de doenças através dos alimentos fornecidos aos consumidores. Para isso é proposta duas investigações, a inspeção ante mortem e a inspeção post mortem (Brasil, 1995).

A inspeção ante mortem consiste na avaliação visual dos animais nas pocilgas de chegada, com avaliação do estado de saúde do rebanho (Bueno, 2012). Já a inspeção post mortem é realizada em todos os suínos abatidos através de exame macroscópico da cabeça, vísceras abdominais, vísceras torácicas, língua, superfície interna e externa da carcaça, cérebro e gânglios linfáticos mais facilmente atingíveis, para retirar da cadeia 
alimentar carcaças de animais que apresentam anomalias, a fim de evitar a comercialização de animais doentes (Herenda et al., 1994).

O processo de evisceração e inspeção de carcaças de suínos deve ocorrer no tempo máximo de 30 minutos após a sangria, juntamente com a oclusão do reto. Para a abertura do animal para a evisceração ocorre com o corte ventral das cavidades abdominal e do tórax (Brasil, 1995). A abertura do animal para a evisceração deve ser feita com corte ventral, das cavidades abdominal e torácica. A faca deve ser provida de protetor para minimizar rupturas em vísceras (Brasil, 1995). As vísceras vermelhas e brancas, além das carcaças, quando forem condenadas serão destinadas para o tratamento pelo frio, calor ou serão condenadas (Brasil, 1995).

O aumento da pressão sobre as normas do bem estar por países compradores da carne suína, torna-se necessário uma padronização de conceitos e uma rigorosa análise crítica do conjunto das condenações dos órgãos durante o abate (Yeates \& Main, 2007). Contudo, ao mesmo tempo que esses órgãos são condenados, formalizam-se os prejuízos econômicos direto para a indústria frigorífica (Fruet, et al., 2013).

O ambiente de frigoríficos é um instrumento do sistema de Vigilância Epidemiológica, pois permite o diagnóstico de enfermidades principalmente as de origens zoonóticas e possibilitam a avaliação de programas de controle e também a erradicação de tais enfermidades (Ungar \& Germano, 1992). A inspeção sanitária no abate de suínos é a primeira linha de defesa após a produção primária, permite que apenas carnes aptas sejam disponibilizadas para o consumo humano, esta é baseada no exame ante mortem do animal e post mortem da carcaça e das respectivas vísceras (Carrijo, et al., 2008), afim de garantir qualidade, salubridade e segurança para o consumidor (Passos \& Kuave, 1996).

$\mathrm{Na}$ inspeção sanitária de carnes constitui uma ação mais preventiva no controle da qualidade higiênico e sanitária dos alimentos, compreendendo diversas atividades que visam proteger a saúde da população através de práticas preventivas de doenças veiculadas por alimentos, com o objetivo de um propósito econômico (Passos \& Kuave, 1996).

$\mathrm{Na}$ inspeção post mortem os órgãos são examinados externamente, além de palpação dos cortes sobre o parênquima para garantir seu destino correto (Bueno, 2012). Órgãos com alterações são condenados, causando perdas econômicas para a indústria frigorífica (Fruet et al., 2013). Os órgãos de suínos são considerados economicamente importante, pois são potenciais fontes de ingredientes alimentares. Ao médio e longo prazo poderão obter maior relevância como subproduto alimentar (Kale et al., 2011).

Uma considerável fração das carcaças de suínos são condenadas nos matadouros frigoríficos brasileiros, seguindo as determinações legais através da fiscalização do Serviço de Inspeção do Ministério da Agricultura, Pecuária e Abastecimento (MAPA), bem como do controle de qualidade das agroindústrias. Tais perdas resultam de condenações parciais ou totais, sendo, a primeira a mais significativa (Ferreira et al., 2012). As perdas econômicas decorridas das condenações recaem tanto sobre os produtores quanto para a indústria (Piffer \& Brito, 1990).

As carcaças podem ser removidas da linha de abate quando estas apresentam qualquer sinal de doença ou outra condição que afete a aparência normal das mesmas. De acordo com o grau da lesão observada haverá a condenação parcial ou total das carcaças afetadas (Andrade et al., 2006).

\section{Resultados e Discussão}

Os órgãos afetados dos animais inspecionados neste trabalho foram: $97,32 \%$ dos pulmões, $24,56 \%$ dos fígados e $6,91 \%$ dos corações apresentavam alguma lesão, sendo julgada como imprópria para o consumo humano e com elevadas perdas econômicas para a empresa.

De acordo com dados da inspeção observados durante o período do abate nos frigoríficos foi avaliado que as principais condenações de vísceras comestíveis, em ordem de ocorrência, foram identificadas no pulmão, fígado e coração (Figura 1).

\section{Análise do pulmão}

Com menor porcentagem foi observado aderência de pleura, atelectasia pulmonar, enfisema pulmonar, abscesso pulmonar, congestão pulmonar e pleuropneumonia, representando apenas 7,18\% das causas de condenações de pulmão (Figura 2). 


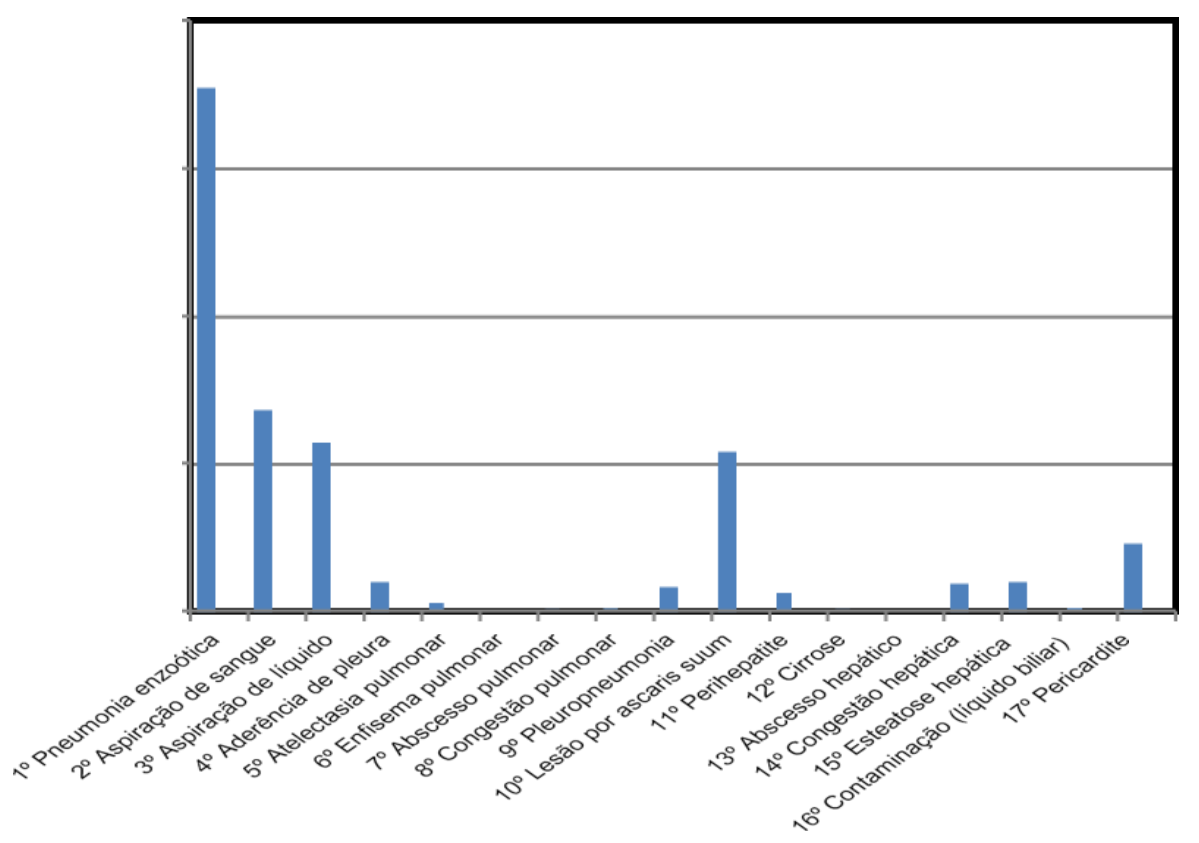

Figura 1. Número de condenações de pulmão, fígado e coração de suínos. Fonte: Dados de pesquisa (2016).

O pulmão representa uma das principais vísceras condenadas, totalizando $97,32 \%$ de condenação, com a pneumonia responsável por grande parte das rejeições de pulmão (Costa et al., 2014). Uma das principais mortes de suínos gerando perda na produção, em particular, são as doenças pulmonares como as pneumonias. Em determinados casos, pode levar a morte, enquanto em outros, essa doença poderá ter efeito negativo na performance do animal (Taylor, 1996).

A literatura cita como as principais causas de condenações de pulmão em abatedouro são aderência de pleura, aspiração de líquido, aspiração de sangue, atelectasia pulmonar, enfisema pulmonar, congestão pulmonar, pleuropneumonia e pneumonia enzoótica (Noyes et al., 1990).

Após o exame visual é realizado a palpação do órgão e posteriormente são incisados os linfonodos apicais para poder confirmar a normalidade. A presença de pneumonia, congestão, enfisema, aspiração, abcessos, verminoses, linfadenite ou contaminação implica na condenação do órgão (Brasil, 2008).

A pleuropneumonia dos suínos é uma doença infecto-contagiosa que causa lesões graves no pulmão e na pleura causada pelo Actinobacilus pleuropneumoniae. Esta doença é caracterizada pela broncopneumonia necrosante, hemorrágica e pleurite fibrinosa, e na forma aguda o animal apresenta lesões fibrinosas no pulmão, extensiva pleurite e pericardite fibrinosa. Em lesões crônicas pode ocorrer sequestros de tecido necrótico e formação de nódulos focais semelhantes a abscessos (Taylor, 1996).

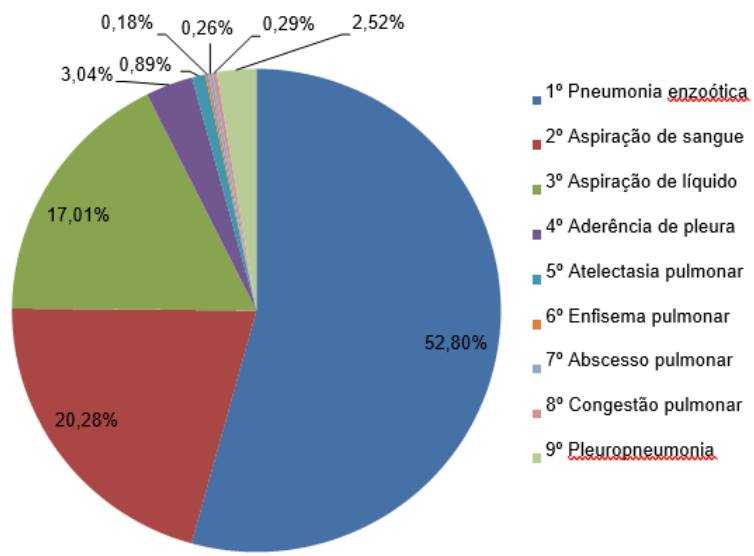

Figura 2. Ocorrência de condenações de pulmão. Fonte: Dados da pesquisa (2016).

Em suínos examinados em matadouros frigoríficos, nos casos crônicos foram observados a presença de nódulos pulmonares encapsulados no parênquima pulmonar, abcessos, pleurite e pericardite fibrinosas com aderências (Sobestiansky et al., 1999).

A aspiração de sangue, é um tipo de tecnopatia muito encontrada em matadouros e frigoríficos (Costa et al., 2014). Esta lesão causada pela aspiração de sangue está diretamente ligada a fatores de ineficiência de tecnologia de abate, sendo uma alteração não patológica que não 
possuem correlação com a carcaça (Fruet et al., 2013). Assim, a aspiração de sangue ocorre quando o colaborador no frigorífico não está devidamente treinado, e juntamente com a secção de carótida e jugular, acaba perfurando a traqueia (Costa et al., 2014).

No trabalho de (Fruet et al., 2013) observou-se 5.511 órgãos condenados, com destaque para as lesões por aspirações de sangue ( $\mathrm{n}=1.231$ animais) podendo estar associados a doenças, contudo a maior frequência pode ter sido causada por ineficiência de tecnologia de abate durante o procedimento de abate (Mellau et al., 2010). A classificação dos pulmões pode ser realizada quanto à presença ou ausência de hepatização pulmonar com características de pneumonia enzoótica, as que em geral, não causam desvios das carcaças da linha de inspeção (Alberton \& Mores, 2008).

A análise da pneumonia enzoótica no Brasil e outros países acontece por dados qualitativos e quantitativos das lesões pulmonares, posteriormente estes dados em programas de computadores calculam a área de pulmão afetada, a prevalência das lesões de pneumonia enzoótica representa a estimativa de perda no ganho de peso diário e na piora da conversão alimentar dos animais (Alberton \& Mores, 2008). É causada pelo Mycoplasma hyopneumoniae onde o pulmão apresenta-se avermelhado e com tecido espessado. O procedimento será a condenação do pulmão na linha de inspeção. Assim, em casos de pneumonia enzoótica complicada deve-se desviar a carcaça e os órgãos para o Departamento de Inspeção Federal (DIF) e este as destinará para a esterilização pelo calor (Sobestiansky et al., 2001).

Para Castro et al. (2014), observou que a pneumonia enzoótica é uma das principais causas de condenação de pulmão em matadouro frigorífico, na qual apresenta baixa mortalidade quando não ocorre complicações por patógenos secundários.

As várias lesões causadas pela pneumonia enzoótica afetam apenas partes dos lobos cranial e acessório. Macroscopicamente, o pulmão de um suíno afetado são vermelho-escuros nas fases iniciais e aparência homogênea pálida-cinzenta nos estágios mais crônicos (Alberton \& Mores $\underline{2008)}$.

Em estudo realizado comparando as lesões de abate com as radiografias da cavidade torácica realizadas durante o período de recria e engorda de suínos foi demonstrado que os suínos que apresentaram pneumonia enzoótica precocemente possuíram menores escores de lesões nas carcaças ao abate (Noyes et al., 1990).

\section{Análise do fígado}

O fígado (Figura 3) é uma das vísceras comestíveis mais condenadas, representando $24,56 \%$, ficando atrás apenas do pulmão. De acordo com (Costa et al., 2014), a lesão por mancha de leite é considerada umas das causas mais importantes de condenação de fígado em abatedouro. Neste estudo as condenações por lesão de Ascaris suum representaram 16,05\% das condenações de fígado. $\mathrm{O}$ descarte do fígado pode ser por abcessos, cirrose, linfadenite, congestão, contaminação, esteatose hepática, migração larval, telangiectasia, perihepatite e verminoses (Nakagawa et al., 1993). O órgão deve ser palpado e comprimido os ductos biliares para conferir a desobstrução (Brasil, 1995).

O fígado é analisado nos abatedouros devido a sua capacidade de modicar o seu aspecto macroscópico alterando a sua consistência, a coloração e o tamanho, em decorrência da ação de fatores químicos e microbiológicos diretamente em seu parênquima (Maclachlan \& Cullen, 1998).

O fígado do suíno é um órgão que possui valor comercial diferenciado, porém, ele se torna susceptível a diversas alterações por possuir função metabólica. Outra condenação neste órgão é a perihepatite resultante de um processo inflamatório do tecido conjuntivo da cápsula hepática, que se apresenta áspera e aderente ao tecido hepático (Moura et al., 2016).

As atuais metodologias usadas na inspeção post-mortem dos animais suínos, apresenta uma técnica segura para avaliar a presença de Ascaris suum constitui em entraves produtivos, sendo responsável pelas perdas econômicas e condenações de fígados (Freitas, 1982). Nessa inspeção o exame ocorre por palpação constatando a presença de manchas branco leitosas no fígado (Bernardo et al., 1990). Em criação de suínos desprovida de orientação técnica e sem preocupação de sanidade animal pode trazer riscos para o segmento de consumidores (Lai et al., 2011).

As principais causas de condenações de fígado de suínos em abatedouro ocorrem por lesão causada pelo Ascaris suum, perihepatite, cirrose hepática, abscesso hepático, congestão hepática, 
esteatose hepática e também por contaminação por líquido biliar (Andrade et al., 2006).

O Ascaris suum é um parasita responsável por lesões no fígado, inspecionado no post mortem com maior impacto no sistema de criação de suínos. Durante a inspeção do fígado de suínos parasitados por este parasita é identificado a presença de "fígado manchado de leite", decorrente da sua migração larval (Fausto et al., 2015). À medida que esta larva se desloca através do fígado causa uma necrose hepatocelular que são acompanhados por inflamações (D'Alencar et al., 2011). A necrose dos hepatócitos é substituída por tecido conjuntivo proporcionando cicatrizes fibrosas na superfície capsular com aparência de áreas pálidas (Zachary, 2013) na linha de abate, esses fígados encaminhados para descarte, devido a seu aspecto repugnante.

Em um experimento foi analisado as questões financeiras entre 2013 e 2014 em um frigorifico de Minas Gerais comprovou que as perdas financeiras neste período foram de $\mathrm{R} \$ 5.644,05$ para a Empresa. Nesse caso cerca de 1,63\% dos animais apresentaram esta lesão, este dado quando comparado ao trabalho foi inferior $(16,05 \%)$ (Freitas, 1982), porém quando comparado foi semelhante a 17,98\% num total de 991 animais abatidos com lesões no fígado obtido (Fruet et al., 2013).

Os animais jovens sadios têm prevalência na produção e no faturamento econômico quando comparado com os animais que apresentam os órgãos comprometidos, mas a condenação gera prejuízo econômico diretamente a indústria e indiretamente ao produtor (Fruet et al., 2013).

D'Alencar et al. (2011) analisando 448 animais mestiços em idade de abate verificou que 16,07\% apresentavam mancha de leite provocado por infecção parasitária. Comparando esses dados com condenações ocorridas na região de Trikala na Grécia, de um total de 3920 fígados observados a única lesão de mancha de leite correspondeu a $0,35 \%$ (Theodoropoulos et al., 1992) valores muito inferiores ao encontrado com 16,05\% devido a lesão por Ascaris suum. Bonesi et al. $\underline{(2003)}$ e Reis et al. (1992) apresentaram resultados variáveis para lesão por mancha de leite, sendo esta considerada uma das causas mais importantes de condenação do fígado.

A passagem das larvas de Ascaris suum, pelo fígado durante o seu ciclo evolutivo confere ao órgão uma aparência indesejável, sendo necessário a condenação do mesmo, sendo que a migração da larva ocasiona destruição do tecido hepático, seguido de hemorragia, necrose e espessamento (Bernardo et al., 1990).

Em outro experimento no Canadá esse percentual foi de $44 \%$ avaliando-se 2.500 animais abatidos (Wagner \& Polley, 1997). Já no Japão, analisando 815 suínos cerca de $38,2 \%$ tiveram parte ou todo o fígado condenado por manchas de leite (Nakagawa et al., 1993). O estudo aponta que as frequências são variáveis em diferentes países, porém os resultados expressam que as manchas de leite são causas importantes na condenação de fígados em abatedouros a nível nacional e internacional.

A literatura demonstra a necessidade da avaliação sobre a eficácia dos programas de controle de infecções por helmintos, onde é necessário ter estratégias de ação no campo através de assistência técnica qualificada e identificação de fatores de riscos nas propriedades (Taylor, 1986), ainda deve considerar o aumento no custo de produção já que piora a conversão alimentar devido a migração das larvas.

Outras lesões de fígado de suínos que ocorrem, porém com menor frequência, representando $8,48 \%$ das condenações são perihepatite, cirrose, abscesso hepático, congestão hepática, esteatose hepática e contaminação por líquido biliar, os mesmos estão descritos (Figura 3).



Figura 3. Ocorrência de condenações de fígado. Fonte: Dados da pesquisa (2016).

Em geral, observa-se alteração do tamanho, da consistência desse órgão que resulta em endurecimento, distorção ao corte e presença de estrias com coloração esbranquiçada (Zachary, 2013) dificultando a sua comercialização.

Nos abatedouros as lesões por atrofia ou hipertrofia dos lobos hepáticos acompanhadas de 
fibrose são consideradas como cirrose. Contudo, o conceito patológico de cirrose é um processo difuso caracterizado por fibrose e conversão da arquitetura normal do fígado em nódulos anormais (Anthony et al., 1978).

Neste estudo a cirrose foi de $2,86 \%$ dos fígados dos suínos, quando comparado com a espécie bovina obteve-se dado similar a 2,60\% de cirrose comprovada em Rondônia de 2004 a 2006 (Locatelli et al., 2012). Em caso de cirrose atrófica ou hipertrófica devem ser condenadas e acompanhadas as amostras para um rigoroso exame de carcaça, para eliminar a possibilidade de doenças infecto contagiosas (Brasil, 1980).

Outras contaminações das carcaças de suínos durante $\mathrm{o}$ abate podem ser oriundas da contaminação por líquido biliar. Esta se apresenta na carcaça com pigmentação verde-amarelada que pode ser encontrada na superfície da carcaça ou órgãos provocados pelos pigmentos biliares, dessa forma o líquido biliar pode ter sido liberado da vesícula biliar durante o processo de evisceração (Wilson, 2009).

\section{Análise do coração}

No presente estudo, as lesões por pericardite apresentaram 6,91\% sendo que essas lesões determinam perdas econômicas no processamento da carcaça e consequentemente nas exportações para os produtores de suínos (Figura 4). Concomitantemente (Coelho et al., 2014), relatou no seu estudo que o percentual de condenações por pericardite variou entre 1,5 a $8,5 \%$ das condenações, dependendo da granja de origem, entretanto as pleurites, as lesões de pericardite são diagnosticadas usualmente durante a inspeção visual no momento do abate.

O coração é um órgão comestível pela composição em componentes essenciais da dieta como aminoácidos, vitaminas e sais minerais. Entretanto, para sua utilização e comercialização para consumo humano deve ser submetido à inspeção higiênico- sanitária para garantir qualidade para os consumidores (Heranda et al., 1994).

O coração é incisado no lado esquerdo cortando também a parede interventricular para que seja observado o lado direito. Usa-se um chuveiro com água corrente a $38-40^{\circ} \mathrm{C}$ para que as estruturas sejam melhor visualizadas. Podem estar presentes contaminação, endocardite, aderência, cisticercose e sarcosporidiose que levam a condenação do órgão (Brasil, 2010).

A análise do coração é realizada pelo exame da superfície externa do coração e faz-se uma incisão longitudinal da base à ponta através da parede do ventrículo esquerdo e do septo interventricular examinando-se as superfícies de cortes, bem como as superfícies mais internas dos ventrículos (Brasil, 2001).

Caso ocorra a inflamação do pericárdio esta é denominada pericardite com lesões sendo facilmente diagnosticada pelo exame visual no abate (Andrade et al., 2006). Outros autores como (Coelho et al., 2014), salientou que a pericardite é observada em septicemia bacteriana, resultando em pericardite fibrinosa. Já nas superfícies visceral e parietal são observados depósitos de fibrina (Zachary, 2013).

A análise de 351.165 suínos, entre 2013 e 2014 observou um prejuízo econômico de $\mathrm{R} \$ 15.871,15$ para o frigorifico analisando apenas as causas de pericardite onde $9,9 \%$ dos animais neste estudo obtiveram este laudo (Freitas, 1982). Em outro trabalho verificaram em 2.013 suínos abatidos cerca $3,42 \%$ apresentaram esta doença, sendo posteriormente descartadas completamente da carcaça (Costa et al., 2014). Ao estudar as condenações de carcaças de suínos (Martinez et al., 2007) observaram que as principais causas de pericardite apresentaram o valor de $0,4 \%$, entre as causas avaliadas.

Assim como as pleurites, as lesões de pericardite são diagnosticadas usualmente durante a inspeção visual no momento do abate, sendo observado a presença de tecido de granulação, caracterizada por proliferação de tecido conjuntivo na superfície do epicárdio (Coelho et al., 2014).

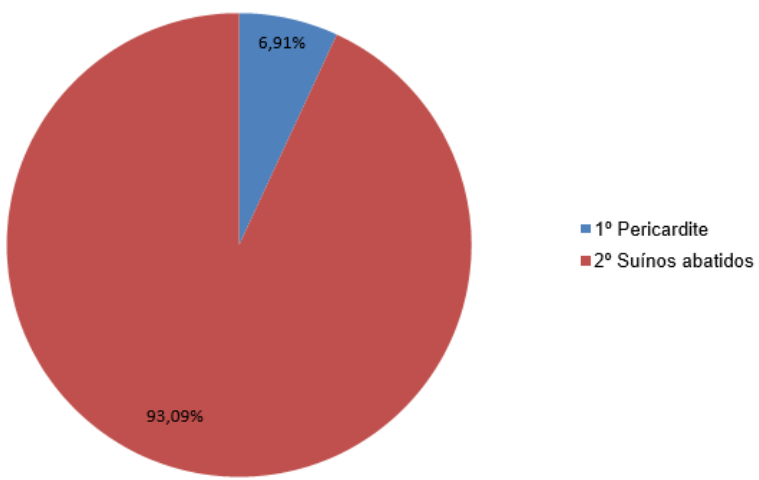

Figura 4. Ocorrência de condenações de coração. Fonte: Dados da pesquisa (2016). 
As pericardites assumem causas de condenações em frigoríficos assim como perdas das carcaças e nas exportações. Os processos inflamatórios no pericárdio podem ser de origem bacteriana (Sciarrone et al., 2007). Os agentes mais comuns são Actinobacluus pleuropneumoniae, A. pyogenes, Haemophilus parasuis, Mycoplasma hyopneumoniae, $M$. hyorhinis, Pausterella multocida e Streptococcus suis (Coelho et al., 2014).

A área lesionada predominantemente de infecção disseminada por via hematógena pode ter origem de permeação linfática de processo inflamatório em tecido adjacente, como o pulmão (Maxie \& Robinson, 2007). Devido à proximidade anatômica entre o pulmão e o coração alguns processos infecciosos podem afetar por contiguidade estas vísceras (Coelho et al., 2014).

Foram investigaram 91 casos de pericardites, $89 \%$ deles foram classificados como crônico e os agentes bacterianos isolados foram Streptococcus spp, Pausterella multocida, Haemophilus parasuins e Streptococcus suis (Coelho et al., 2014).

\section{Condenações de vísceras}

Após a evisceração, as carcaças serão separadas com uso de uma serra em corte longitudinal, ao longo da coluna vertebral até a papada. A serra é esterilizada a cada carcaça em água a $82,2^{\circ} \mathrm{C}$ para eliminar qualquer contaminação (Brasil, 1980).

O RIISPOA condena as vísceras principalmente pela aderência de pleura, aspiração de líquido, aspiração de sangue, atelectasia pulmonar, enfisema pulmonar, congestão do pulmão, pleuropneumonia, pneumonia enzoótica, lesão por migração de Ascaris suum, perihepatite, cirrose hepática, abscesso de fígado, congestão hepática, esteatose hepática, contaminação por líquido biliar e pericardite.

Os órgãos afetados e condenados dos animais inspecionados no presente estudo foram diagnosticados cerca de $97,32 \%$ dos pulmões, $24,56 \%$ dos fígados e $6,91 \%$ dos corações apresentavam algum tipo de lesão, com elevadas perdas econômicas para a empresa suinícola (Figuras $2, \underline{3}$ e 4 ).

Vale ressaltar que grandes condenações das vísceras comestíveis podem agregar prejuízos para a agroindústria, considerando que tais condenações sejam provenientes de doenças ou baixa tecnologia para a correta realização do abate. As principais causas em ordem de ocorrência foram o fígado e posteriormente o coração.

Castro et al. (2014), em seu levantamento bibliográfico verificou que a maioria das condenações de pulmão decorreram de pneumonia enzoótica.

No frigorífico pode acontecer problemas operacionais durante o abate resultando em danos nas carcaças ou condenações de órgãos, também foi observado que a aspiração por sangue é a segunda maior causa de condenação de pulmão (Fruet et al., 2013)

Os resultados apresentaram o fígado $24,56 \%$ como a víscera mais condenada quando comparado com o coração. A lesão caracterizada por "mancha de leite" é considerada umas das causas mais importantes de condenação de fígado em abatedouro (Costa et al., 2014),

Neste levantamento do frigorifico onde foi realizado a coleta dos dados, a condenação de fígados por hepatites parasitárias teve maior expressão no primeiro semestre, devido à patogênese migratória de Ascaris suum estar associada à infecção posterior ao período chuvoso, com temperaturas e umidades ideais para disseminação de ovos no solo.

Outras lesões de fígado de suínos ocorridas nesse frigorífico representaram $8,48 \%$ das condenações neste órgão como a perihepatite, cirrose, abscesso hepático, congestão hepática, esteatose hepática e contaminação por líquido biliar (Taylor, 1996).

Ressalta que esta alta incidência de condenações realizadas durante a inspeção pode estar associada a falhas no processo tecnológico de abate, falha no processo de vacinação dos suínos além de falhas na biossegurança de algumas doenças ou até mesmo falha no manejo da granja (Andrade et al., 2006).

\section{Fatores relacionados as condenações de carcaça}

A pneumonia enzóotica ocupa lugar de destaque na patologia suína devido a intensidade de animais dentro de um sistema de produção. Associa que esta doença tem grau e severidade que dependem, dentre outros fatores, das características dos agentes e da imunidade do rebanho, sobretudo das condições ambientais em 
que estão sendo criados (Sobestiansky et al., 2001).

Dessa maneira, os fatores de manejo, ambiente e nutricional desempenham papel fundamental na ocorrência e também na severidade de doenças, já que os mesmos estão presentes tanto em rebanhos com como sem problemas com agentes infecciosos (Svensmark et al., 1989).

\section{Setor de graxaria ou subprodutos}

Este setor fica localizado anexo ao matadouro com a finalidade de promover o aproveitamento dos subprodutos gerados durante $\mathrm{o}$ abate, fabricando farinha e óleo. Depois de armazenado, todos os resíduos de toalete, restos de cortes de carcaça, vísceras e ossos não comestíveis são levados até as galerias onde será moído e colocado em digestores.

$\mathrm{O}$ digestor é a máquina do setor de farinhas e óleos que fornece calor para o cozimento dos subprodutos (Ferroli et al., 2000). Após o cozimento, o produto será retirado manualmente e será escorrido para escoar e posteriormente será prensado para produzir uma torta e extrair totalmente o óleo.

A moagem da torta em farinha fina será incorporada nas fábricas de ração e aos demais farelos. Antes da comercialização será adicionado antioxidante e anti-Salmonella para a conservação do produto (Ferroli et al., 2000).

\section{Considerações gerais}

As condenações de vísceras representam grande perda econômica para os pequenos e médios comerciantes da cadeia suína. As lesões de maior prevalência na condenação de pulmão, fígado e coração foram respectivamente, pneumonia enzoótica, aspiração por sangue, lesão por Ascaris suum seguida por pericardite.

As patologias infecciosas que denotam importantes causas na condenação de pulmões possuem alta prevalência nas granjas e a prevenção de tais patologias requer campanhas de conscientização dos produtores o controle sanitário dos animais e a intensificação do acompanhamento dos fiscais de defesa sanitária na linha de abate.

O manejo sanitário na granja implica diretamente no controle adequado dos processos tecnológicos de abate, assim com a realização do treinamento de funcionários afim de reduzir a prevalência das lesões encontradas durante a inspeção da carcaça poderá minimizar as perdas econômicas na indústria e no também para o produtor de suínos, além de garantir a segurança alimentar para os consumidores.

\section{Referências bibliográficas}

ABIPECS, Associação Brasileira da Industria Produtora e Exportadora de Carne Suína. 2011. Disponível em: <http://www.abipecs.org.br/> . Acesso em: 24 de novembro, 2017.

ABPA, Associação Brasileira de Proteína Animal. 2014. Disponível em: http://abpa-br.com.br>. Acesso em: 29 de novembro, 2017.

Alberton, G. C. \& Mores, M. A. Z. 2008. Interpretação de lesões no abate como ferramenta de diagnóstico das doenças respiratórias dos suínos. Acta Scientiae Veterinariae, 36(1), 95-99.

Andrade, N. da S., Cruz, A. L., de Vinhaes Torres, P. E., Edinggton, L. N. \& Caregnato, C. Z. 2006. Principais causas de condenação de órgãos de suínos em matadouro com inspeção estadual em Simões Filho -BA. 2006. Higiene Alimentar, 25, 194-195.

Anthony, P. P., Ishak, K. G., Nayak, N. C., Poulsen, H. E., Scheuer, P. J. \& Sobin, L. H. 1978. The morphology of cirrhosis. Recommendations on definition, nomenclature, and classification by a working group sponsored by the World Health Organization. Journal Clinical Pathology, 31, 395-414.

Bernardo, T. M., Dohoo, I. R. \& Ogilvie, T. A. 1990. Critical Assessment of abattoir surveillance as a screening test for swine ascariasis. Canadian. Journal Veterinary Research, 54(1), 274-277.

Bonesi, G. L., Scalone, B. C. V., Werner, O. \& Aristófanes, R. 2003. Lesões hepáticas em bovinos de abatedouro frigorífico. Higiene Alimentar, 106,78-83.

Brasil, Ministério da Agricultura e do Abastecimento. 1980. Regulamento da Inspeção Industrial e Sanitária de Produtos de Origem Animal (Aprovado pelo decreto $\mathrm{n}$. 30690, de 20.03.52, alterado pelo decreto $\mathrm{n}$. 1255, de 25.06.52). Ministério da Agricultura, Brasília, BR.

Brasil, Ministério da Agricultura Pecuária e Abastecimento. 2008. Regulamento da Inspeção Industrial e Sanitária de Produtos de Origem Animal (Aprovado pelo decreto $\mathrm{n}$. 
30.691, de 29.03.52, alterados pelos decretos $n$. 1255 de 25.06.62, 1236 de 01.09.94, 1812 de 08.02.96, 2244 de 04.06.97. Ministério da Agricultura, Brasília, BR.

Brasil, Ministério da Agricultura, do Abastecimento e da Reforma Agrária. 1995. Portaria n. 711 de 01 de nov. Normas Técnicas da instalação e equipamentos para abate e industrialização de suínos.

Brasil, Ministério da Agricultura, do Abastecimento. 2001. Regulamento de Inspeção Industrial e Sanitária de produtos de origem animal.

Brasil, Ministério da Saúde. 2010. Departamento de Ciência e Tecnologia. Secretaria de Ciência, Tecnologia e Insumos Estratégicos. Doenças negligenciadas: estratégias do Ministério da Saúde. Revista Saúde Publica, 44(1), 200-202.

Bueno, L. S. 2012. Condenações de carcaças suínas em abatedouro comercial (Dissertação de Mestrado). Universidade Federal da Grande Dourados. Disponível em: $<$ https://tede.ufgd.edu.br/jspui/bitstream $/$ tede/446/5/LESLEYBUENO.pdf $>$. Acesso em: 6 de junho, 2018.

Carrijo, K. F., Nascimento, E. R., Santos, I. F., Chagas, E., Kuiava, L. \& Tortelly, R. 2008. Comparação entre os diagnósticos pela inspeção sanitária post mortem e histopatologia da pneumonia enzoótica suína: estudo de caso-controle. Revista Brasileira de Ciência Veterinária, 15(2),77-81.

Castro, B. G., Socolosky, S. N. G., Zane, A. C., Santos, R dos., Gomes, S. C. \& Silva, R. A. C. 2014. Estudo retrospectivo de causas sanitárias de condenações de carcaça e vísceras de suínos em frigorífico de Sinop. Scientific Eletronic Archives, 6, 36-44.

Coelho, C. F., Zlotowski, P., Andradem C.P., Borowski, S. M., Gaggini, T. S., Driemeier, D. \& Barcellos, D. E. S. N. 2014. Pericardite em suínos ao abate no Rio Grande do Sul: Avaliação de agentes bacterianos e lesões associadas. Pesquisa Veterinária Brasileira, 34(7), 643-648.

Costa, R. A., Leite, P. A. G., Barros, C. G. G. \& Lopes, G. M. B. 2014. Principais causas de condenações em vísceras comestíveis de suínos abatidos em um matadouro frigorífico sob inspeção estadual na região de AlagoinhasBA. Revista Veterinária. e Zootecnia, 21(2), 616-623.
D’Alencar, A. S., Farias, M. P. O., Santos, F. L., Alves, L. C. \& Faustino, M. A. G. 2011. Lesões renais em suínos de abatedouros. Revista Veterinária e Zootecnia, 3, 07-15.

Fausto, M. C., Oliveira, I. C., Fausto, G. C., Carvalho, L. M., Valente, F. L. \& Campos, A. K. 2015. Ascaris suum in pigs of the Zona da Mata, Minas Gerais, Brasil. Revista Brasileira de Parasitologia Veterinária, 24(3), 375-378.

Ferreira, T. Z., Sesterhenn, R. \& Kindlein, L. 2012. Perdas econômicas das principais causas de condenações de carcaças de frangos de corte em Matadouros-frigoríficos sob Inspeção Federal no Rio Grande do Sul. Acta Scientiae Veterinariae, 40(1), 1-6.

Ferroli, P. C. M., Neto, M. F. \& Castro, J. E. E. 2000. Fábricas de subprodutos de origem animal: a importância do balanceamento das cargas dos digestores de vísceras. Produção, 10(2), 05-20.

Freitas, M.G. 1982. Helmintologia Veterinária (6a ed. 396 p.). Precisa Editora Gráfica LTDA, Belo Horizonte, Minas Gerais, BR.

Fruet, A. P. B., Scortegagna A., Fabricio, E. A., Kirinus, J. K., Dorr, A. C. \& Nomberg, J. L. 2013. Perdas econômicas por condenação de órgãos suínos em matadouros sob serviço de inspeção municipal. Revista Eletrônica em Gestão, Educação e Tecnologia Ambiental, 11, 2307-2312.

Giovanni, L. M., Bueno, R., Bordin, R, A., Vargas, G. D. \& Sampaio, K. 2014. Descrição das condenações de carcaças suínas em abatedouro inspecionado pelo serviço de inspeção federal no estado de São Paulo. Revista Eletrônica Thesis, Ano XI(22), 46-51.

Herenda, D., Chambers, P. G., Ettriqui, A., Seneviratna, P \& Silva, T. J. P. 1994. Manual on meat inspection for developing countries. Food and Agriculture Organization, Roma, IT.

IBGE, Instituto Brasileiro de Geografia e Estatística. 2017. Indicadores IBGE. Estatística da produção pecuária. Disponível em: $<$ https://agenciadenoticias.ibge.gov.br/agenc ia-sala-de-imprensa/2013-agencia-denoticias/releases/20523-em-2017-cresce-abatede-bovinos-e-suinos-mas-cai-o-defrangos.html>. Acesso em: 6 de junho, 2018.

Kale, M. C., Aral, Y. \& Aydin, E. 2011. Determination of by-product economic values for slaughtered cattle and sheep. Kafkas Üniversitesi Veteriner Fakültesi Dergisi, 17(4), 551-556. 
Lai, M., Zhou, R. Q., Huang, H. C. \& Hu, S. J. 2011. Prevalence and risk factors associated with intestinal parasites in pigs in Chongqing, China. Research Veterinary Science, 91(3), 121-124.

Locatelli, J. S., Deus, I. R., Vian, V. S. \& Schons, S. V. 2012. Estudo Retrospectivo de Condenação de Fígado de Bovino em Frigorífico com S.I.F no Município de Jarú-RO no período de 2004 a 2006. Ciência \& Consciência, 2.

Maclachlan, N. J. \& Cullen, J. M. 1998. Fígado, sistema biliar e pâncreas exócrino. In: Thomson, R. G. Patologia Veterinária Especial (p. 265-298). Artmed, Porto Alegre, Rio Grande do Sul, BR.

Martinez, J., Jaro, P.J., Aduriz, G. \& Gomes, E.A. 2007. Carcass condemnation causes of growth retarded pigs at slaughter. Veterinary Journal, 174, 160-164.

Maxie M. G. \& Robinson W. F. 2007. Cardiovascular system. In: Maxie, M. G. (Ed.), Jubb, Kennedy, and Palmer's. Pathology of Domestic Animals (vol. 3, 5a ed.). Saunders Elsevier, Edinburgh, UK.

Mellau, L. S. B., Nonga, H. E. \& Karimuribo, E. D. 2010. A slaughterhouse survey of lung lesions in slaughtered stocks at Arusha, Tanzania. Preventive Veterinary Medicine, 97, 77-82.

Moura, S. V., Lopes, M. S., Schmitt, E., Rebassa, V. R., Scwegler, E., Goulart, M. A., ... Côrrea, M. N. 2016. Avaliação do diagnóstico de perihepatite em suínos após o abate e sua relação com os níveis de enzimas hepáticas. Semina: Ciências Agrárias, 35(3), 1351-1360.

Nakagawa, J., Kamitsuji, M. K., Pieri, J. C., Villas Bôas, R. L. 1993. Efeitos do bagaço, decomposto por ação de biofertilizante, na cultura da alface. Científica, 21(1), 169-177.

Noyes, E. P., Feeney, D. A. \& Pijoan, C. 1990. Comparison of the effect of the pneumonia detected during lifetime with pneumonia detected at slaughter on growth in swine. Journal of American Medicine Veterinary Association, 197, 1025-1029.

Passos, M. H. C. R. \& Kuaye, A. Y. 1996. Avaliação dos laudos analíticos, de alimentos de Campinas-SP, no período de 1987 a 1993. Higiene Alimentar, 10(41), 7-10.

Piffer, I. A. \& Brito, J. R. F. 1991. Descrição de um modelo para avaliação e quantificação de lesões pulmonares de suínos e formulação de um índice de classificação de rebanhos (doc. 23). EMBRAPA-CNPSA, Concórdia, Santa Catarina, BR.

Reis, R., Lemos, J. M. \& Cavalcante, J. E. 1992. Estudo das lesões pulmonares de suínos de abate. Arquivo Brasileiro de Medicina e Veterinária Zootecnia, 5, 407-418.

Sciarrone, F., Stella, S. \& Bonardi, S. 2007. Valutazione della efficacia di dissanguamento delle carcasse di suini affetti da pericardite: studio preliminare. Annali della Facoltà di Medicina Veterinaria di Parma, 27, 165-172.

SEAB, Secretaria de Estado da Agricultura e do Abastecimento. 2013. Suinocultura - Análise da conjuntura agropecuária. Disponível em: < http://www.agricultura.pr.gov.br/arquivos/File /deral/Prognosticos/SuinoCultura_2012_2013. pdf $>$. Acesso em: 12 de maio, 2018.

Sobestiansky, J., Martins, M. I. S., Barcellos, D. E. S. H. \& Sobral, V. B. G. M. 1991. Formas anormais de comportamento dos suínos: possiveis causas e alternativas de controle (Circular Técnica, 14). EMBRAPA-CNPSA, Concórdia, Santa Catarina, BR.

Svensmark, B., Nielsen, K., Willeberg, P. \& Jorsal, S. E. 1989. Epidemiological studies of piglet diarrhoea in intensively managed danish sow herds. II. Post-weaning diarrhoea. Acta Veterinary Scanch, 30, 55-62.

Taylor, J. D. 1996. The lungs. In: Sims, L. D. \& Glastonbury, J. R. W. (Eds). Patology of the pigs: a diagnostic guide (cap. 14, p. 219-238). Agriculture Victoria, Pig Research and Development Corporation, Bendigo, Vic, AU.

Theodoropoulos, G., Petrakos, G., Kantzoura, V. \& Kostopoulos. J. 1992. Abattoir Condemnation due to Parasitic Infections and its economic implications in the Region of Trikala, Greece. Journal of Veterinary Medicine, 49, 281-284.

Ungar, M. L. \& Germano, P. M. L. 1992. Prevalência da cisticercose bovina no estado de São Paulo. Revista de Saúde Pública, 26, 167172.

Wagner, B. \& Polley, L. 1997. Ascaris suum prevalence and intensity: an abattoir survey of market hogs in Saskatchewan. Veterinary Parasitology, 73, 309-313.

Wilson, W. G. 2009. Wilson's inspeção prática de carne. Roca, São Paulo, BR.

Yeates, J. W. \& Main, D. C. J. 2007. Assessment of positive welfare: A review. The Veterinary 
Journal. UK. Disponível em: $<$ http: www.sciencedirect.com> Acesso em: 10 de fevereiro, 2018.

Zachary, J. F. 2013. Bases da patologia em veterinária (2a ed.). Elsevier, Rio de Janeiro, BR.
Article History:

Received 11 February 2018

Accepted 24 April 2018

Available online 8 June 2018

License information: This is an open-access article distributed under the terms of the Creative Commons Attribution License 4.0, which permits unrestricted use, distribution, and reproduction in any medium, provided the original work is properly cited. 